\title{
Comparison of Surface Air Temperature between Observation and Reanalysis Data over Eastern China for the Last 100 Years
}

\author{
Siqi ZHANG \\ Chinese Academy of Meteorological Sciences, China Meteorological Administration, China \\ Laboratory for Climate Studies, National Climate Center, China Meteorological Administration, China \\ Guoyu REN \\ Department of Atmospheric Science, School of Environmental Studies, China University of Geosciences, China \\ Laboratory for Climate Studies, National Climate Center, China Meteorological Administration, China
}

Yuyu REN

Laboratory for Climate Studies, National Climate Center, China Meteorological Administration, China

and

Xiubao SUN

Laboratory for Climate Studies, National Climate Center, China Meteorological Administration, China

(Manuscript received 6 May 2018, in final form 10 October 2018)

\begin{abstract}
This study aims to improve the understanding of the differences in surface air temperature data between observations and reanalysis since the beginning of the 20th century and addresses the reanalysis data error. The anomaly correlation, standard deviation, and linear trend of temperature during 1909-2010 in eastern China were analyzed based on the homogenized observation data obtained from 16 stations and two sets of 20th century monthly mean surface air temperature reanalysis data (20CR and ERA20C). The results show that the interannual and decadal variabilities were consistent between reanalysis and observations in eastern China after 1979. The reanalysis data exhibited a large fluctuation during the 1960s. The average 20CR temperature was lower than the observations during 1920-1950. The inter-annual and decadal variability for winter and spring were consistent with the observations. The correlation and standard deviation ratio between the reanalysis and observations demonstrated a high consistency of their inter-annual variability and dispersion. The ERA20C data were generally closer to the observations than the 20CR data for the period 1979-2010. The linear trends of surface air temperature showed clear warming in both reanalysis datasets and the observations but the reanalysis trends were significantly smaller than the observational trends for annual mean temperature and most of the seasonal mean temperatures after the 1950s. Overall, ERA20C was generally closer to the observational temperatures than 20CR during 1909-2010, but this consistency does not necessarily indicate ERA20C's suitability for climate change research because of the systematic bias referenced to the observational data.
\end{abstract}

Corresponding author: Guoyu Ren, Laboratory for Climate Studies, National Climate Center, China Meteorological Administration, Beijing 100081, China

E-mail: guoyoo@cma.gov.cn, zhangsq@cma.gov.cn

J-stage Advance Published Date: 29 October 2018

(C) The Author(s) 2019. This is an open access article published by the Meteorological Society of Japan under a Creative Commons Attribution 4.0 International (CC BY 4.0) license (https://creativecommons.org/licenses/by/4.0). 
Keywords observation; reanalysis; eastern China; temperature; 20th century; inter-comparison

Citation Zhang, S., G. Ren, Y. Ren, and X. Sun, 2019: Comparison of surface air temperature between observation and reanalysis data over eastern China for the last 100 years. J. Meteor. Soc. Japan, 97, 89-103, doi:10.2151/ jmsj.2019-004.

\section{Introduction}

A series of reanalysis datasets have been developed since the 1990s, such as NCEP-NCAR (Kalnay et al. 1996), NCEP-DOE (Kanamitsu et al. 2002), CFSR (Saha et al. 2010), NASA-MERRA (Rienecker et al. 2011), ERA-40 (Uppala et al. 2005), ERA-Interim (Dee et al. 2011; Uppala et al. 2008), JRA-25 (Onogi et al. 2007), and JRA-55 (Kobayashi et al. 2015). However, the earliest reanalysis product began in 1948 and therefore could not be used in climate change research that focuses on the early 20th century. However, in recent years, the United States and the European Union implemented a series of atmospheric reanalysis projects that span the entire 20th century or even earlier than that. The United States 20CR (Compo et al. 2011) is an outcome of the 20th Century Reanalysis Project from NOAA, and the European ERA20C (Poli et al. 2013) is an outcome of the ERACLIM project from ECMWF. The reanalysis data have advantages in terms of coverage in oceanic, polar, and plateau regions and length of time series. However, they also have the disadvantages of incorporating the errors from the numerical prediction model, the assimilation process, and observation system change factors (Bengtsson et al. 2004; Zhao et al. 2010; Thorne and Vose 2010; Zhao et al. 2015; Parker 2016; Lahoz and Schneider 2014; Zhou et al. 2018). To avoid the false trends caused by changes in the observation system and internal incoordination of data, 20CR assimilates surface observations of synoptic pressure, monthly sea surface temperature, and sea ice distribution, whereas ERA20C assimilates observations of surface pressure and surface marine winds only. The surface air temperature is not as reliable as air pressure partly because of the uncertainties associated with the changes in the observational system (Kistler et al. 2001). However, the issue of how to evaluate the potential of reanalysis data over 100 years for climatology and climate change research has not been given sufficient attention because of the lack of high-quality observation data at the regional scale.

In recent years, many scholars have examined the global and regional scale changes and evaluated the applicability of 20CR and ERA20C. Ferguson and Villarini (2012) found that the temperature of 20CR in the central region of the United States was discontinuous from 1940 to 1950 , but the temperature of observation data was continuous in the same time period. Fan and Liu (2013) indicated the consistency of climatology in the southern hemisphere between 20CR and the observation data during 1979-2010 but found significant differences from that of HADSLPv2 during 1897-1920. Poli et al. (2016) indicated that the ERA20C ranging from the north to south latitudes within $65^{\circ}$ was $1 \mathrm{~K}$ colder than the ship observation data at night during 1900-2010. Studies have also focused on China. For example, by comparing with other reanalysis data, Song and Zhou (2012) evaluated 20CR with respect to the East Asian summer monsoon variability and found a higher consistency with other reanalysis data, but it failed to reveal the decadal-scale variation of weakened East Asia summer monsoon since the late 1970s. Liu and Fan (2014) compared surface air temperature between 20CR and observation data from 160 stations in China and found that the correlations were generally better for temperature than for precipitation. Zhou et al. (2018) discussed the main factors influencing regional warming modeling in current reanalysis products. Their results showed that $80 \%$ of the temperature differences between reanalysis and observations could be attributed to station and model-grid elevation differences. The aforementioned studies pointed out the uncertainties of $20 \mathrm{CR}$ and ERA20C in different regions during different periods. These may be due to the limited assimilation sources, which produced different results for different periods and regions (Xu et al. 2001). Therefore, it remains necessary at present to evaluate the applicability of the long-term temperature characteristics and linear trends of these two reanalysis datasets in China.

The data inhomogeneity of some observational stations may be caused by the instrumentation, the different periods of observation records, and station relocations. These issues have led to uncertainties in the study of warming during the 20th century. Considering the adjustments for inhomogeneity, there are three main Chinese temperature observation datasets 
with long time series. Tang et al. $(2005,2009)$ used the mean values of maximum and minimum temperatures, avoiding the discontinuity caused by using different time observation records, to calculate averages as monthly and annual mean values, but did not account for the inhomogeneity caused by station relocation. Li et al. (2010) used long time series observation data from several neighboring countries, and homogenous data from the national reference climate stations and basic meteorological stations to establish annual and seasonal mean temperature anomaly sequences from 1900 , but the inhomogeneities caused by station relocation were not resolved. Cao et al. (2013) used data from 18 relatively integrated stations in eastern China and adjusted for the inhomogeneities caused by station relocation to establish the annual average temperature anomaly sequence. It showed that the linear trend of unadjusted surface air temperature was slightly smaller than that of adjusted surface air temperature by $\sim 0.23^{\circ} \mathrm{C} / 100$ a from $1909-2010$. It means that the inhomogeneous time series appeared to underestimate warming trends during the last 100 years and illustrated the uncertainty of inhomogenization on the assessed linear trend at a 100-year scale. This dataset is considered to be the most suitable and homogenized observation data for use in the temperature change studies at the 100-year scale in eastern China; however, the urbanization bias from station observations are exaggerated in the data series because of the homogenization procedure and the consideration of observations of only a small number of big cities (Ren et al. 2017).

Because of the uncertainty of reanalysis data in climate change research especially in estimates of linear trends of climatic variables including surface air temperature, there is a need to evaluate the reliability of reanalysis data by comparing with high-quality, long-term observational data. Based on the temperature dataset of Cao et al. (2013), the surface air temperature of two reanalysis datasets from 1909 to 2010 (20CR and ERA20C) were evaluated in the current study. Because there was a larger positive deviation in the linear trend of long-term observation temperature by Cao et al. (2013), the results of Tang et al. $(2005,2009)$ were also used as a reference for the linear trends. This study is to assess the reliability of the two sets of reanalysis data in estimating longterm trends of surface air temperature. In addition, this study is different from the previous works. First, the 20CR and ERA20C data series from 1909 to 2010 are much longer than those usually used in previous researches; second, we used a new homogenized 100+ year surface air temperature data series to evaluate the applicability of these two reanalysis datasets in the monitoring and detection of long-term temperature change in China, and in particular focused our attention on the long-term trends of temperature. The research findings will provide an indication of the reliability and applicability of the two long-term reanalysis datasets in eastern China which is important for future climate change research.

\section{Data and methods}

To compare the observation and reanalysis data, it was necessary to first establish annual and seasonal mean temperature sequences from $20 \mathrm{CR}$ and ERA20C in the location of the observation stations. The difference of annual and seasonal mean surface air temperature anomalies between reanalysis data (referred to as REA) and homogenized observation data (referred to as ADJ), and the standard deviations, correlations and linear trends of the annual and seasonal mean surface air temperature of the two reanalysis datasets and ADJ, were then analyzed and compared. In this study, we focused on objectively assessing the applicability of the surface air temperature from the two reanalysis datasets for eastern China. The monthly mean observation data used in this study were produced by the NMIC/CMA in 2013 (Cao et al. 2013). The data were collected from different sources of long sequence observations, then merged together and quality controlled, using the standard sequence method, partial least-squares regression, and the multiple regression method for interpolation to provide data from missing stations and periods. The extended version of the penalized maximal $F$-test (PMFred) algorithm and the penalized maximal $T$-test (PMTred) algorithm (Wang 2008) were used as the main test methods. In addition, two-phase regression (Easterling and Peterson 1995) and the sliding $T$-test homogenization method were applied as the auxiliary inspection methods, and metadata were used to confirm and correct the discontinuities. The number of observation stations was 4, 12 and 16 before 1900 and in 1909 and 1916, respectively, so we selected $1909-2010$ as the research period for observational temperature. There were 12 stations available for use before 1916. The 16 stations under a $1000 \mathrm{~m}$ altitude in eastern China (Fig. 1) were selected in this study because the length of time of observational records was unequal. In the linear trends analysis, we also used the results of Tang et al. $(2005,2009)$ (henceforth ADJ-T), who used data from a total of 600 and 231 stations in eastern China after and before 1950 , respectively. 


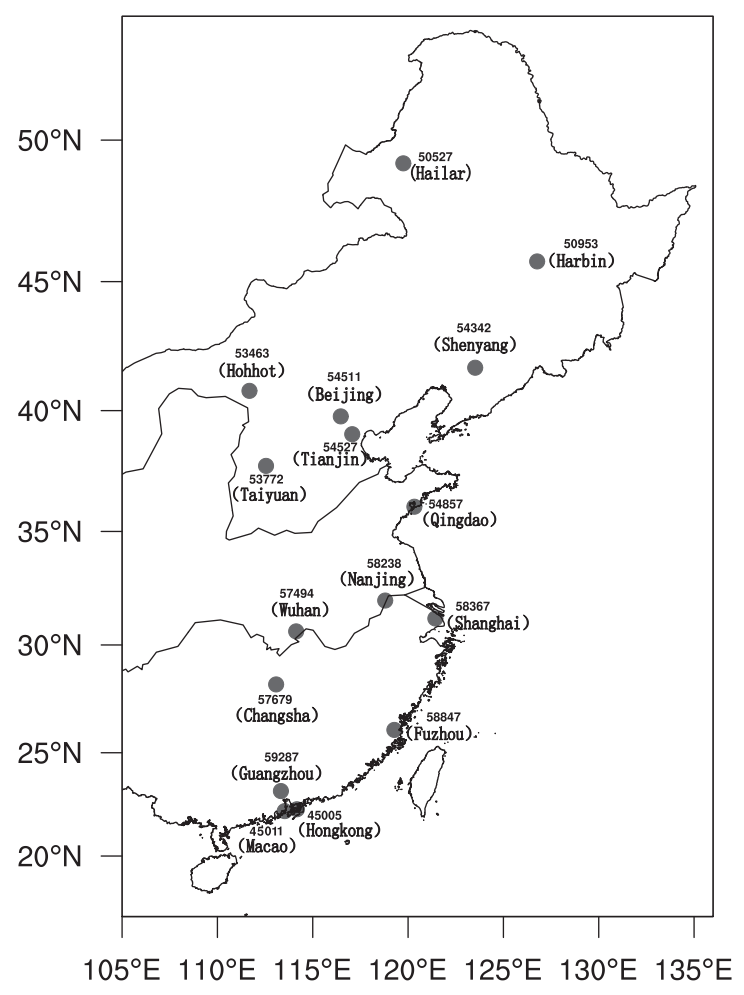

Fig. 1. Distribution of the 16 observation stations in eastern China.

The monthly mean temperatures of the two reanalysis datasets, 20CR (monthly mean from 1871 to 2012) and ERA20C (monthly mean from 1900 to 2010) collectively referred to as REA, were derived from NOAA and ECMWF, respectively. The spatial resolution of $20 \mathrm{CR}$ is $2.0^{\circ} \times 2.0^{\circ}$ and that of ERA20C is $1.5^{\circ}$ $\times 1.5^{\circ}$. The grid box center locations nearest to the observational stations were selected for the comparison with observation station data. We also selected 19092010 as the research period.

The annual mean temperature was calculated from the observation and reanalysis data based on 12 monthly mean values. When calculating the mean temperature sequences of eastern China, some stations located in close proximity (such as Beijing and Tianjin, Hong Kong, Macao, and Guangzhou) were averaged firstly and then an arithmetic average was calculated between the time series and the other station series. The correlation between ERA20C and ADJ was compared with the correlation between $20 \mathrm{CR}$ and ADJ, and the standard deviations and linear trends of REA and ADJ were also compared in the manuscript.

The standard deviation ratio $(S D R)$ represents the similarity in standard deviation between REA and ADJ (the overbars indicate mean value):

$$
S D R=\frac{\sqrt{\frac{1}{n} \sum_{i=1}^{n}\left(R E A_{i}-\overline{R E A}\right)^{2}}}{\sqrt{\frac{1}{n} \sum_{i=1}^{n}\left(A D J_{i}-\overline{A D J}\right)^{2}}} .
$$

The correlation coefficient $(R)$ between REA and ADJ represents the degree of similarity in the annual variability:

$$
R=\frac{\sum_{i=1}^{n}\left(R E A_{i}-\overline{R E A}\right)\left(A D J_{i}-\overline{A D J}\right)}{\sqrt{\sum_{i=1}^{n}\left(R E A_{i}-\overline{R E A}\right)^{2}} \sqrt{\sum_{i=1}^{n}\left(A D J_{i}-\overline{A D J}\right)^{2}}} .
$$

A value of $S D R$ or $R$ close to 1 reflects a close similarity between REA and ADJ.

The significant correlation coefficient of climate trend $(S)$ represents the quantitative degree of temperature rise and fall under climate change.

$$
S=\frac{\sum_{i=1}^{n}\left(R E A_{i}-\overline{R E A}\right)\left(i-\frac{n+1}{2}\right)}{\sqrt{\sum_{i=1}^{n}\left(R E A_{i}-\overline{R E A}\right)^{2}} \sqrt{\sum_{i=1}^{n}\left(i-\frac{n+1}{2}\right)^{2}}} .
$$

According to the regression theory, the trend value (a) is calculated as follows:

$$
\alpha=S \frac{\sqrt{\frac{1}{n} \sum_{i=1}^{n}\left(R E A_{i}-\overline{R E A}\right)^{2}}}{\sqrt{\frac{1}{n} \sum_{i=1}^{1}\left(i-\frac{n+1}{2}\right)^{2}}} .
$$

\section{Comparison of ADJ and REA}

\subsection{Comparison of average temperatures}

The annual and seasonal mean surface air temperature anomalies over eastern China from the ADJ and REA datasets (Fig. 2) demonstrated that the reanalysis datasets describe the observational temperature characteristics in the inter-annual variation of the 20th century. The temperature of ERA20C was significantly higher than that of ADJ from 1965 to 1975. Furthermore, the annual mean temperature of $20 \mathrm{CR}$ was $1{ }^{\circ} \mathrm{C}$ lower than ADJ in $1920-1950$, with a large fluctuation in 1963-1968. The anomaly and variation characteristics for ERA20C were generally closer to ADJ than those of $20 \mathrm{CR}$. The annual mean anomaly 

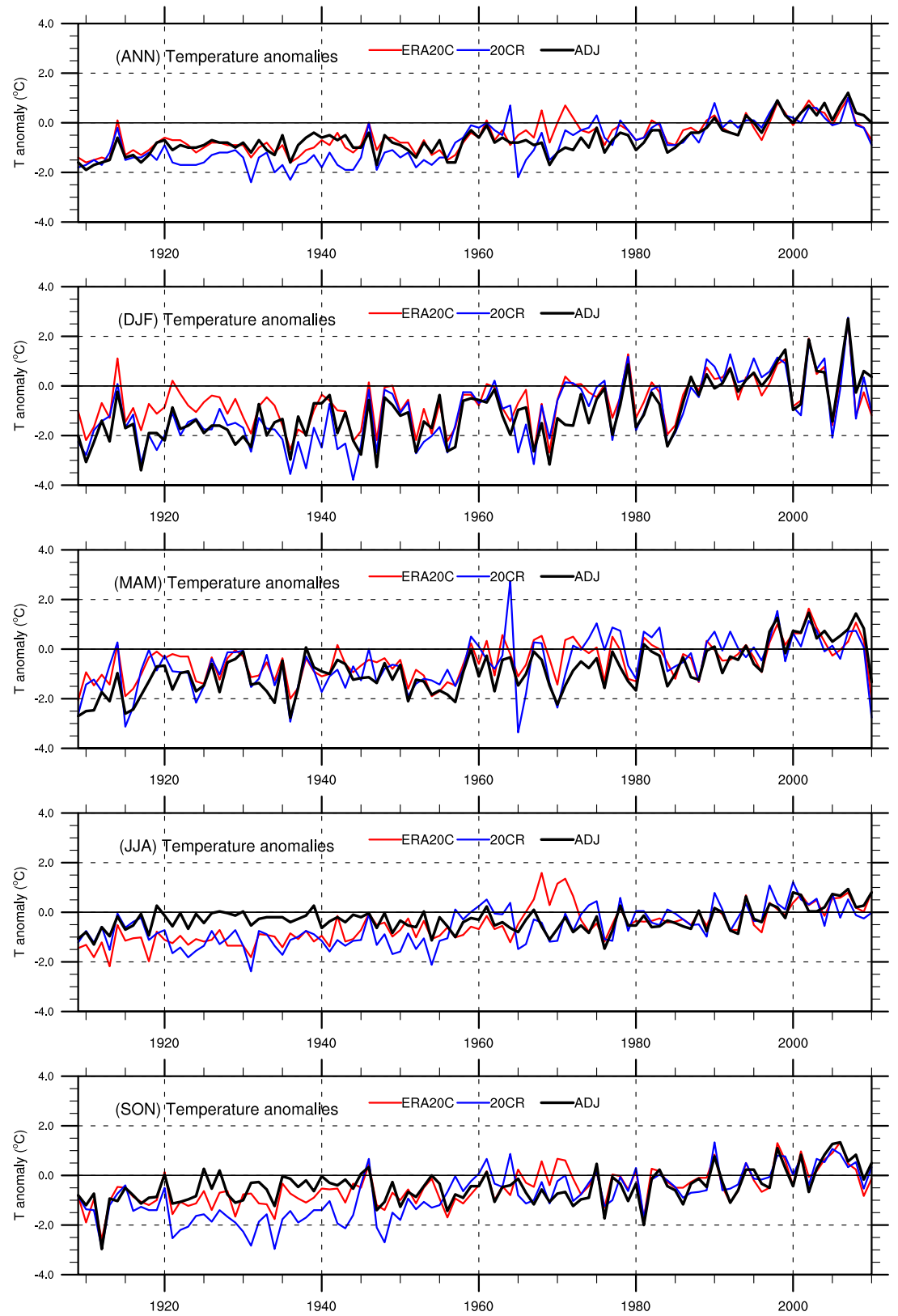

Fig. 2. Annual and seasonal mean surface air temperature anomalies (units: ${ }^{\circ} \mathrm{C}$ ) of eastern China during $1909-$ 2010 derived from observation stations (ADJ) and two reanalysis datasets (ERA20C and 20CR) (ANN, annual; DJF, winter; MAM, spring; JJA, summer; SON, autumn).

characteristics of REA and ADJ were also reflected in the seasonal anomalies; REA was $0.5-1{ }^{\circ} \mathrm{C}$ lower than ADJ in summer and autumn between 1920 and 1950, and ERA20C was higher than ADJ in winter before the 1930s and lower than ADJ before 1925 in spring. In addition, the annual mean temperature of ERA20C was higher than ADJ during 1965-1975, which was mainly affected by aestival factors. The fluctuation in 20CR during 1963-1968 was mainly affected by the spring temperature.

In order to focus on short-term inter-annual variations, the linear trends of annual and seasonal mean 

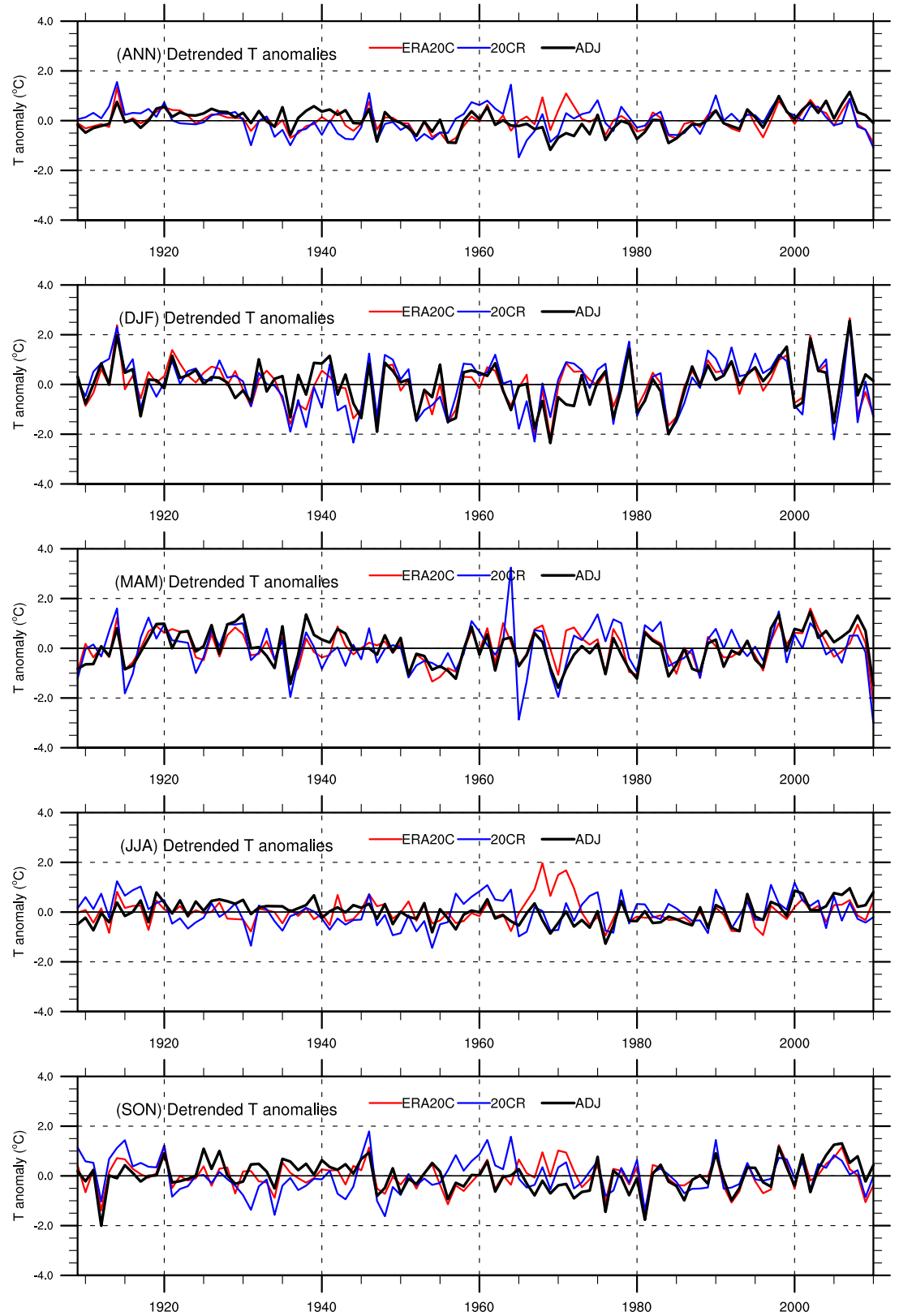

Fig. 3. Annual and seasonal mean surface air temperature anomalies (units: ${ }^{\circ} \mathrm{C}$ ) which were removed the trend of eastern China during 1909-2010 derived from observation stations (ADJ) and two reanalysis datasets (ERA20C and 20CR) (ANN, annual; DJF, winter; MAM, spring; JJA, summer; SON, autumn).

surface air temperature in eastern China during 19092010 were removed from the anomalies series for both ADJ and REA datasets (Fig. 3). It was notable that the annual mean temperature of ERA20C was significantly higher than that of ADJ from 1965 to 1975. This was mainly caused by the higher temperature in JJA and SON. Furthermore, the annual mean temperature of 20CR had a large fluctuation in 1963-1968, which was mainly due to the larger inter-annual variability of temperature in MAM. 20CR was generally higher than that of ADJ from 1955 to 1965 in JJA and SON. Overall, the detrended annual and seasonal mean surface 
Table 1. Annual mean surface air temperature of Standard deviation ratio $(S D R)$ and correlation coefficient $(R)$ over eastern China derived from observation stations and two reanalysis datasets (ERA20C and 20CR) during the periods 1909-2010, 1951-2010, and 1979-2010 (respective thresholds of $0.19,0.36$, and 0.41 at the $95 \%$ level)

\begin{tabular}{cccccc}
\hline \multirow{2}{*}{ Period } & \multicolumn{2}{c}{ ERA20C } & & \multicolumn{2}{c}{$20 \mathrm{CR}$} \\
\cline { 2 - 3 } \cline { 5 - 6 } & $R$ & $S D R$ & & $R$ & $S D R$ \\
\hline $1909-2010$ & 0.81 & 0.96 & & 0.74 & 1.28 \\
$1951-2010$ & 0.76 & 0.87 & & 0.74 & 1.07 \\
$1979-2010$ & 0.88 & 0.85 & & 0.80 & 0.88 \\
\hline
\end{tabular}

air temperature anomalies showed that the reanalysis datasets could in a larger extent describe the observational temperature characteristics in the inter-annual variation of the 20th century. The correspondence of the reanalysis data series with observations was better in winter and spring than in summer and autumn.

According to the above results, 20CR and ERA20C had a high consistency with ADJ especially after 1975 in describing the annual characteristics. However, there were great fluctuations in REA during the 1960s and 1970s, with large differences between 20CR and ADJ before the $1950 \mathrm{~s}$. Of the two reanalysis datasets, ERA20C was generally closer to ADJ.

\subsection{Correlation and ratio of standard deviation}

The findings presented in Section 3.1 indicated uncertainties associated with assessing the applicability of the reanalysis datasets. These uncertainties arise as a result of the differences between REA and ADJ at different periods. Therefore, in this section, we compared the similarity of inter-annual variability and standard deviation between REA and ADJ in different periods.

Table 1 shows the $R$ values and $S D R$ values between annual mean temperature of ERA20C or 20CR and ADJ for the periods 1909-2010, 1951-2010, and 1979-2010. The correlation of REA and ADJ in each period was statistically significant, indicating the similar inter-annual variability to ADJ. The R of ERA20C and ADJ was higher than that of 20CR and ADJ in all three periods ( $\mathrm{R}$ values were 0.88 and 0.80 respectively in 1979-2010, 0.76 and 0.74 in 1951-2010, and 0.81 and 0.74 in 1909-2010). This shows that ERA20C was closer to ADJ in terms of inter-annual variability. The REA and ADJ temperature $S D R$ shows that the standard deviations of ERA20C were less than ADJ during the three periods. The $S D R$ (1.28 and 1.07) of 20CR and ADJ during 1909-2010 and 1951-2010

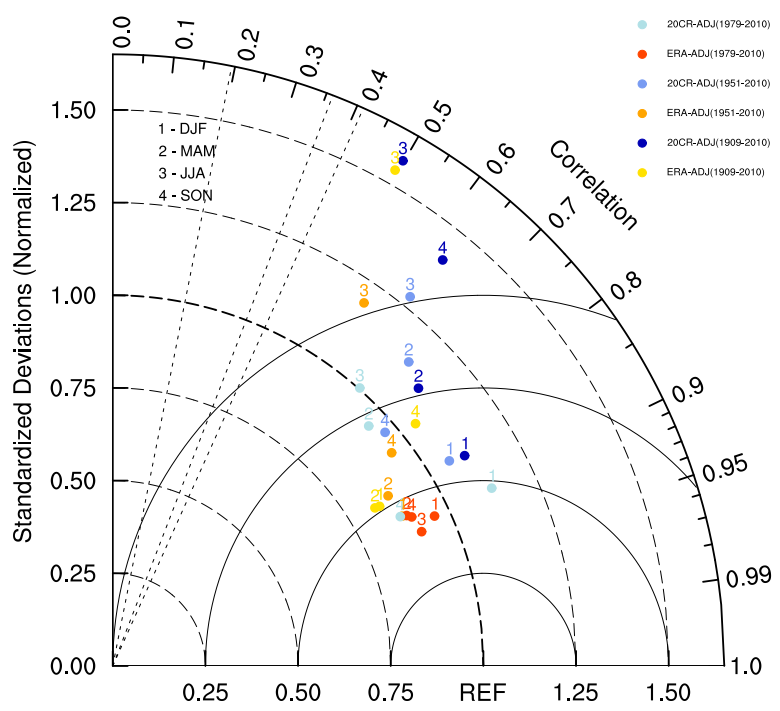

Fig. 4. Taylor diagram of seasonal mean surface air temperature averaged in China derived by reanalysis datasets (ERA20C and 20CR) and observations (ADJ) based on the periods 19092010, 1951-2010, and 1979-2010 (DJF, winter; MAM, spring; JJA, summer; SON, autumn).

were higher than those of ERA20C and ADJ, which indicates that the dispersion of ERA20C was generally lower than ADJ. The dispersion of 20CR was larger than that of ADJ because of the low temperatures before 1950. In order to compare the correlation and standard deviations, a Taylor diagram was used to illustrate the similarity of the annual and seasonal variability, and dispersion derived from REA and ADJ during 1909-2010, 1951-2010, and 1979-2010 (Fig. 4). The results demonstrated that the seasonal correlation of ADJ and REA was statistically significant at different times (with respective thresholds of $0.19,0.36$, and 0.41 at the $95 \%$ level). The correlation of REA and ADJ in most of the winter and spring was higher than in summer and autumn, and the consistency of REA and ADJ was greatest for the winter inter-annual variability, with the lowest agreement in summer. The $S D R$ from REA and ADJ showed that the seasonal standard deviations of ERA20C were lower than ADJ, except for summer and autumn in 1909-2010 and summer in 1951-2010, with values of $0.8-1.0$. The standard deviation of $20 \mathrm{CR}$ was consistently higher than ADJ, except for spring and autumn in 1979-2010 and 1951-2010. The greatest bias of standard deviation of REA and ADJ occurred in summer of 1909-2010, indicating poor dispersion 

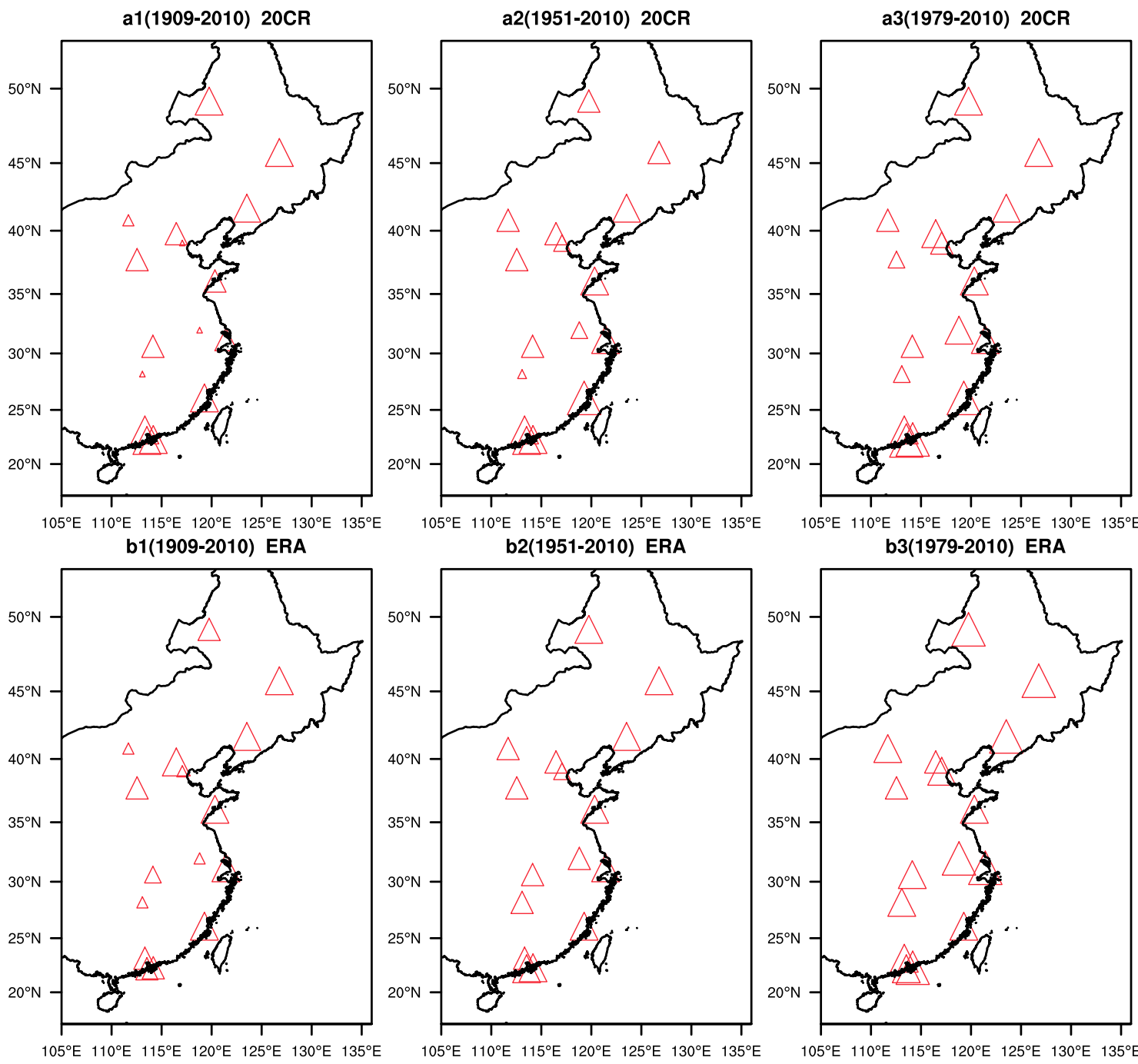

b3(1979-2010) ERA

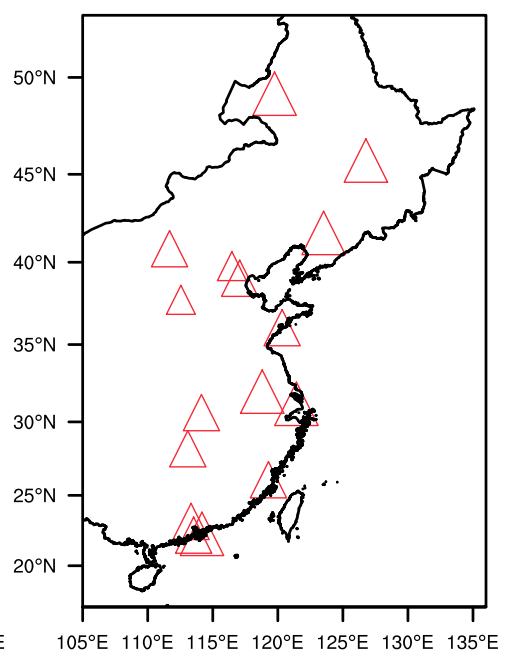

0.85-1

0.7-0.85

$0.55-0.7$

$\triangle 0.4-0.55$

$\triangle 0.25-0.4$

$\triangle 0-0.25$

Fig. 5. Spatial distribution of temperature correlation $(R)$ for 1909-2010, 1951-2010, and 1979-2010 over eastern China based on reanalysis datasets (ERA20C and 20CR) and observations (ADJ).

of the reanalysis data in summer during this period. Figure 5 shows the spatial distribution of the temperature correlation coefficient $(R)$ for 1909-2010, 19512010, and 1979-2010 across eastern China derived from REA and ADJ. The $R$ values for all stations were statistically significant at the $95 \%$ level in the three periods except for Nanjing station of 20CR from 1909 to 2010 ( $R$ of 0.11 ), indicating the general similarity between REA and ADJ when describing the annual variability characteristics. The $R$ values in Nanjing, Changsha, Tianjin, and Hohhot were lower than in other stations during 1909-2010 and 1951-2010. For example, the $R$-value of 20CR and ADJ from 1909 to 2010 in Nanjing, Changsha, Tianjin, and Hohhot stations was $0.11,0.24,0.25$, and 0.35 , respectively. During 1951-2010, the Nanjing, Changsha, and Tianjin stations had $\mathrm{R}$ values of $0.36,0.4$, and 0.51 between 20CR and ADJ, respectively, which were significantly lower than the other stations in the same period.

Figure 6 shows annual and seasonal mean surface air temperature anomalies (units: ${ }^{\circ} \mathrm{C}$ ) of Nanjing, Changsha, Tianjin, and Hohhot during 1909-2010 derived from ADJ and ERA20C and 20CR. The annual 

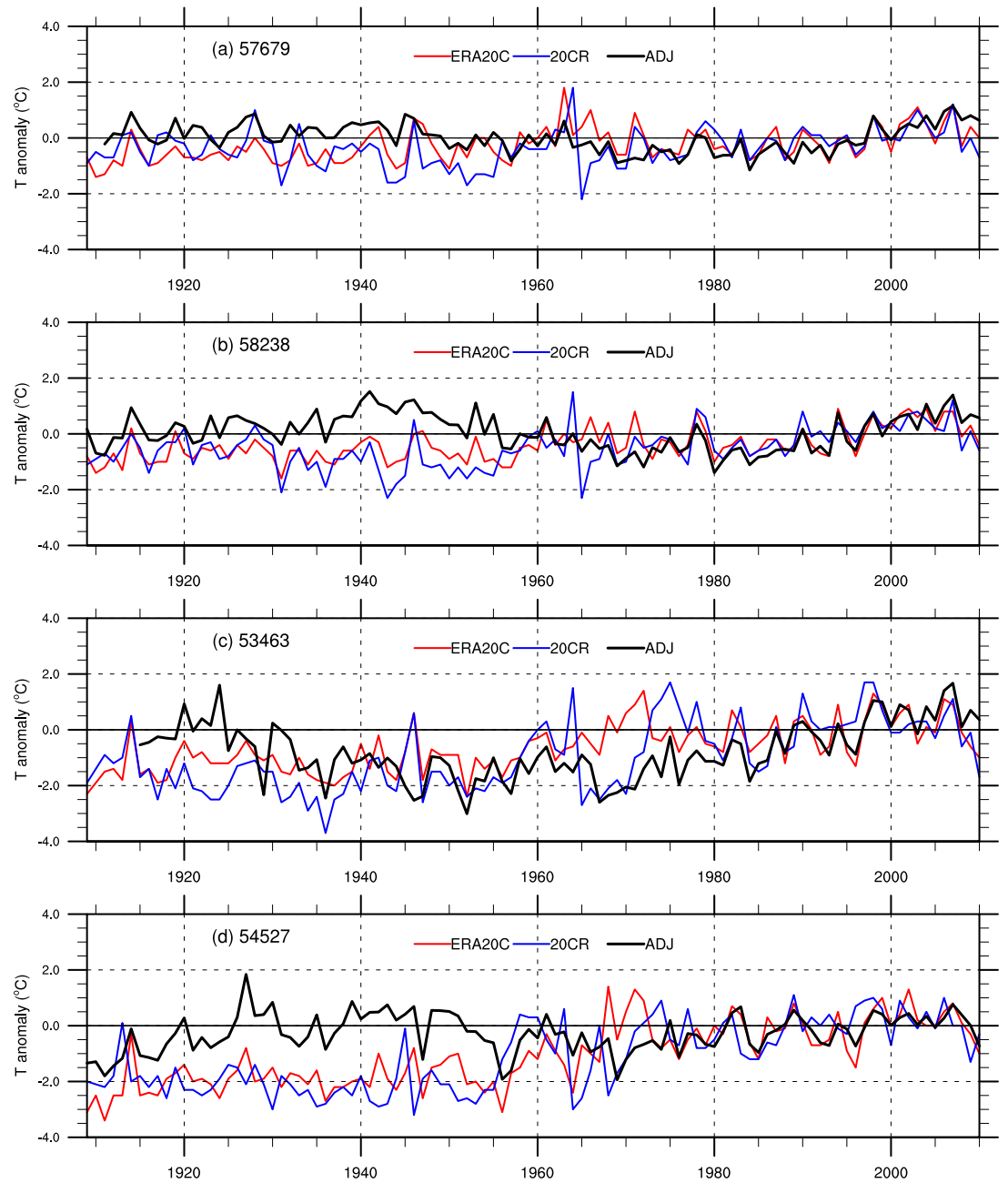

Fig. 6. Annual and seasonal mean surface air temperature anomalies (units: ${ }^{\circ} \mathrm{C}$ ) of Nanjing, Changsha, Tianjin, and Hohhot during 1909-2010 derived from ADJ and ERA20C and 20CR (a: Changsha (57679), b: Nanjing (58238), c: Hohhot (53463), d: Tianjin (54527)).

mean temperature of REA was lower than ADJ before 1960 at Changsha, Nanjing, and Tianjin. The temperature of Hohhot was lower than ADJ before 1940 and higher in 1960-1980. This may be the main reason for the low correlation between REA and ADJ at the four stations, and it suggests that REA may not be suitable for long-term climate change analyses including the early 20th century data at least at these four stations. The 20CR assimilates surface observations of synoptic pressure, sea surface temperature and sea ice, whereas ERA20C assimilates observations of surface pressure and surface marine winds only. The difference may have caused the different temperatures between the two reanalysis datasets, and the different levels of uncer- tainties of the reanalysis data as compared to the ADJ.

Comparison of the REA and ADJ SDR for the spatial distribution of annual average temperature (Fig. 7) indicated that the standard deviations of $20 \mathrm{CR}$ were higher than ADJ in North China and East China from 1909 to 2010, including Beijing and Tianjin, with ratios of 1.68 and 1.78 , respectively. The standard deviations of 20CR were also higher than that of ADJ in North China, East China and South China stations during 1951-2010. The standard deviations in the north stations were higher than those of ADJ during 1979-2010 except for Hailar and Hohhot, and those in southern China (except for Macao) were smaller than ADJ. The standard deviations of the annual mean 

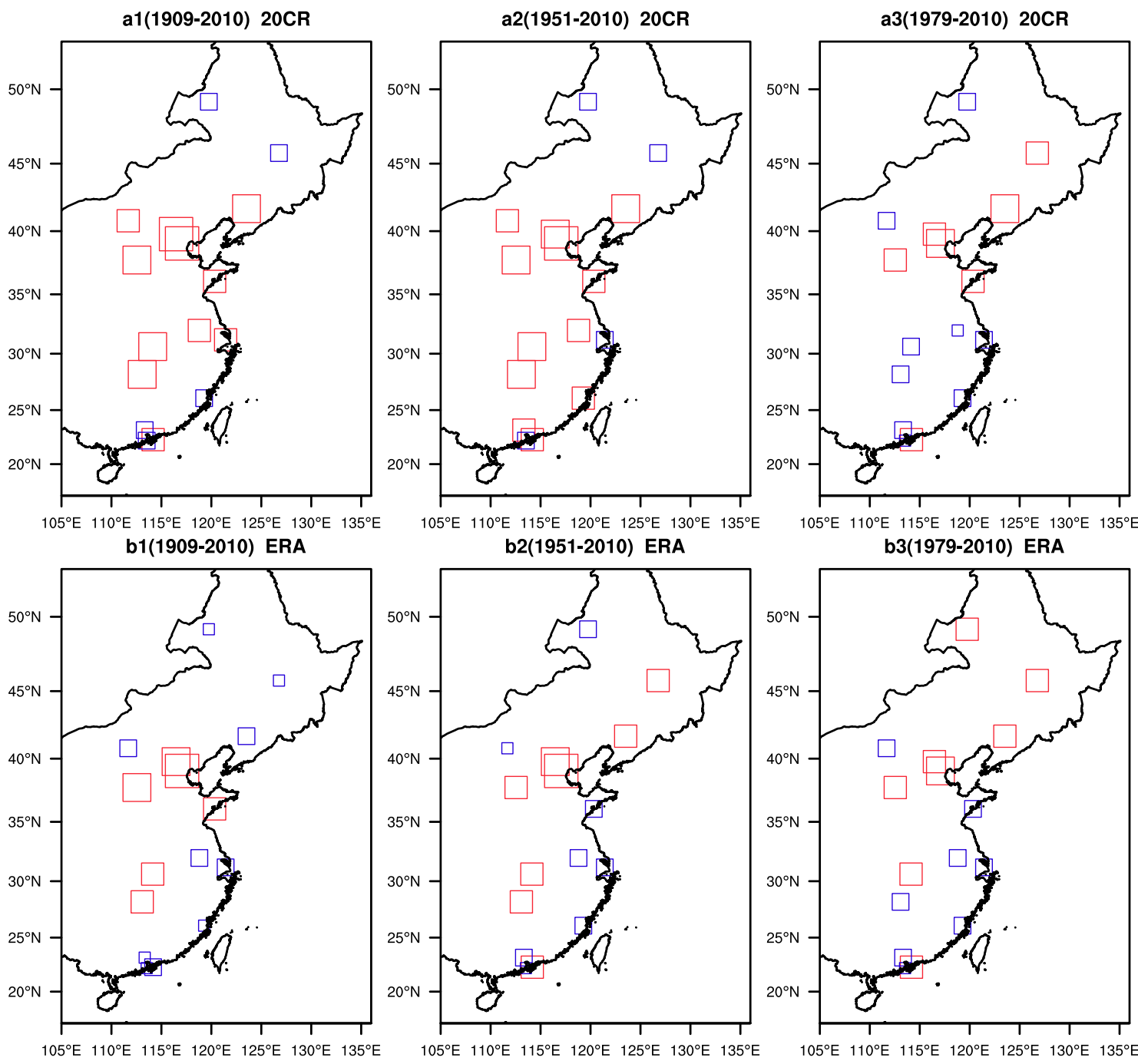

b3(1979-2010) ERA

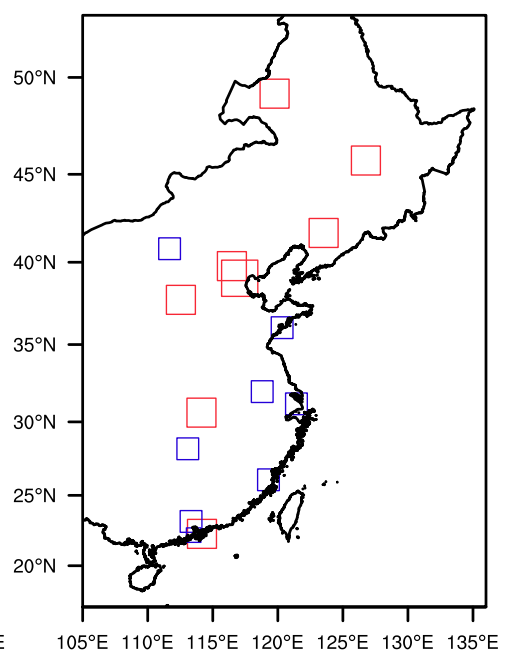

$>1.5$

$1.25-1.5$

$1-1.25$

$0.75-1$

$\square \quad 0.5-0.75$

ㅁ $<0.5$

Fig. 7. Spatial distribution of temperature standard deviation ratio (SDR) for the periods 1909-2010, 1951-2010, and 1979-2010 over eastern China based on reanalysis datasets (ERA20C and 20CR) and observations (ADJ).

temperature of ERA20C were lower than those of ADJ in the northeast inner Mongolia, and southern coastal stations during 1909-2010 and 1951-2010. The main distribution of the standard deviation was higher than ADJ in northern China during 1979-2010, but smaller in southern China.

According to the above results, the inter-annual and decadal variability and dispersion were generally consistent between REA and ADJ in eastern China. The $R$ values of ADJ with ERA20C were higher than those with 20CR in each time period, and the standard deviations were lower than ADJ. The standard devi- ations of 20CR were higher than the ADJ in 19092010 and 1951-2010. A similar result has also been noted in previous research. Zhou et al. (2018) showed that the reanalysis products underestimated the surface air temperature over most of the regions in China. These discrepancies were especially pronounced over the Tibetan Plateau and middle China. In addition, the correlations between the annual surface air temperature anomalies in the reanalysis products and the observations are reasonably strong. The simulated time series of temperature anomalies over eastern China are depicted most accurately by the reanalysis. ERA20C 
Table 2. Trend of temperature change for the reanalysis and observation datasets

(* indicates that the change was significant at the $95 \%$ level; unit: $\left.{ }^{\circ} \mathrm{C}(10 \mathrm{yr})^{-1}\right)$

\begin{tabular}{|c|c|c|c|c|c|}
\hline \multicolumn{2}{|c|}{ Period } & ERA20C & 20CR & ADJ & ADJ-T \\
\hline \multirow{5}{*}{$1909-2010$} & Annual & $0.15^{*}$ & $0.20 *$ & $0.15^{*}$ & $0.10^{*}$ \\
\hline & Winter & $0.14 *$ & $0.26^{*}$ & $0.25 *$ & $0.17 *$ \\
\hline & Spring & $0.13 *$ & $0.17 *$ & $0.20 *$ & $0.15^{*}$ \\
\hline & Summer & $0.18^{*}$ & $0.15^{*}$ & $0.06^{*}$ & $0.03 *$ \\
\hline & Autumn & $0.15^{*}$ & $0.23^{*}$ & $0.11^{*}$ & $0.07 *$ \\
\hline \multirow{5}{*}{$1951-2010$} & Annual & $0.20 *$ & $0.24 *$ & $0.29 *$ & $0.23 *$ \\
\hline & Winter & $0.27 *$ & $0.36^{*}$ & $0.43 *$ & $0.36^{*}$ \\
\hline & Spring & $0.20 *$ & $0.21 *$ & $0.36^{*}$ & $0.25 *$ \\
\hline & Summer & $0.25^{*}$ & $0.19 *$ & $0.18 *$ & $0.18 *$ \\
\hline & Autumn & $0.28^{*}$ & $0.21 *$ & $0.22 *$ & $0.20^{*}$ \\
\hline \multirow{5}{*}{$1979-2010$} & Annual & $0.26^{*}$ & $0.25^{*}$ & $0.49 *$ & $0.44 *$ \\
\hline & Winter & 0.17 & $0.25^{*}$ & $0.53 *$ & $0.41 *$ \\
\hline & Spring & $0.30^{*}$ & 0.08 & $0.58 *$ & $0.53 *$ \\
\hline & Summer & $0.35^{*}$ & $0.20 *$ & $0.41 *$ & $0.36^{*}$ \\
\hline & Autumn & $0.28^{*}$ & $0.38^{*}$ & $0.51 *$ & $0.46^{*}$ \\
\hline
\end{tabular}

displays better performance than 20CR. In general, ERA20C was more similar to ADJ than 20CR. The temperature of the $20 \mathrm{CR}$ was lower than observation data before 1950, leading to the low similarity in inter-annual variability and the high dispersion. The bias between REA and ADJ was mainly generated in summer and autumn, with minimal deviation in winter.

\subsection{Comparison of the linear trend}

Table 2 presents the annual and seasonal linear trends of eastern China mean temperatures during 1909-2010, 1951-2010, and 1979-2010 derived from ADJ and REA. Because of the large positive deviation of $\mathrm{ADJ}$ in reflecting the long-term temperature trend (Cao et al. 2013; Zhao et al. 2014; Wang et al. 2014; Ren et al. 2017), we also referred to the results of Tang et al. $(2005,2009)$ (ADJ-T) for comparison of the linear trend. The average annual trends of REA, $\mathrm{ADJ}$, and ADJ-T at different periods were statistically significant at the $95 \%$ level. The trend for ADJ was $0.15^{\circ} \mathrm{C}(10 \mathrm{yr})^{-1}$, which was equal to that of ERA20C and less than the trend of 20CR during 1909-2010, and that of ADJ-T was $0.10^{\circ} \mathrm{C}(10 \mathrm{yr})^{-1}$, which was less than the trend of REA. During 1951-2010 and 1979-2010, the trends of REA were lower than ADJ, and those of ADJ were higher than ADJ-T. In terms of seasonal mean trends of REA and observations at different periods, ADJ and ADJ-T were statistically significant at the $95 \%$ level in each period. In winter and spring, and most summer and autumn periods, the trends of ADJ were higher than ADJ-T, and seasonal trends of REA during 1909-2010, 1951-2010, and 1979-2010 were significant in summer and autumn. Overall, for most seasons from 1909 to 2010, the trends of $20 \mathrm{CR}$ were greater than the observations, and the trends of ERA20C were larger than those of ADJ and ADJ-T for summer and autumn. However, during 1951-2010 and 1979-2010, the trends of the observations were greater than REA.

In order to further compare the annual mean trends of REA and ADJ at different periods, Fig. 8 shows spatial distribution of temperature change of the 16 stations during 1909-2010 1951-2010, and 1979-2010. From 1909 to 2010 (Figs. 6a1-c1), it can be concluded that the warming trends in northern stations were higher than those in southern stations. Moreover, temperature of REA in each station showed increasing trends, and also exceeded a $95 \%$ significance threshold. Except for Nanjing and Changsha, which showed decreasing trends, the annual mean temperature in ADJ significantly increased at most stations. From 1951 to 2010 (Figs. 6a2-c2), the temperatures of REA and ADJ datasets for most stations increased significantly, with 20CR mainly concentrated in the south of Northeast China, ERA20C in the north of the Yangtze River, and an increasing trend in the ADJ dataset at each station during 1909-2010. In the north of the Yangtze River, the ERA20C temperature changes were more similar to those of ADJ, while 20CR and ADJ were closer in the south of the Yangtze River. From 1979 to 2010 (Figs. 6a3-c3), the signifi- 


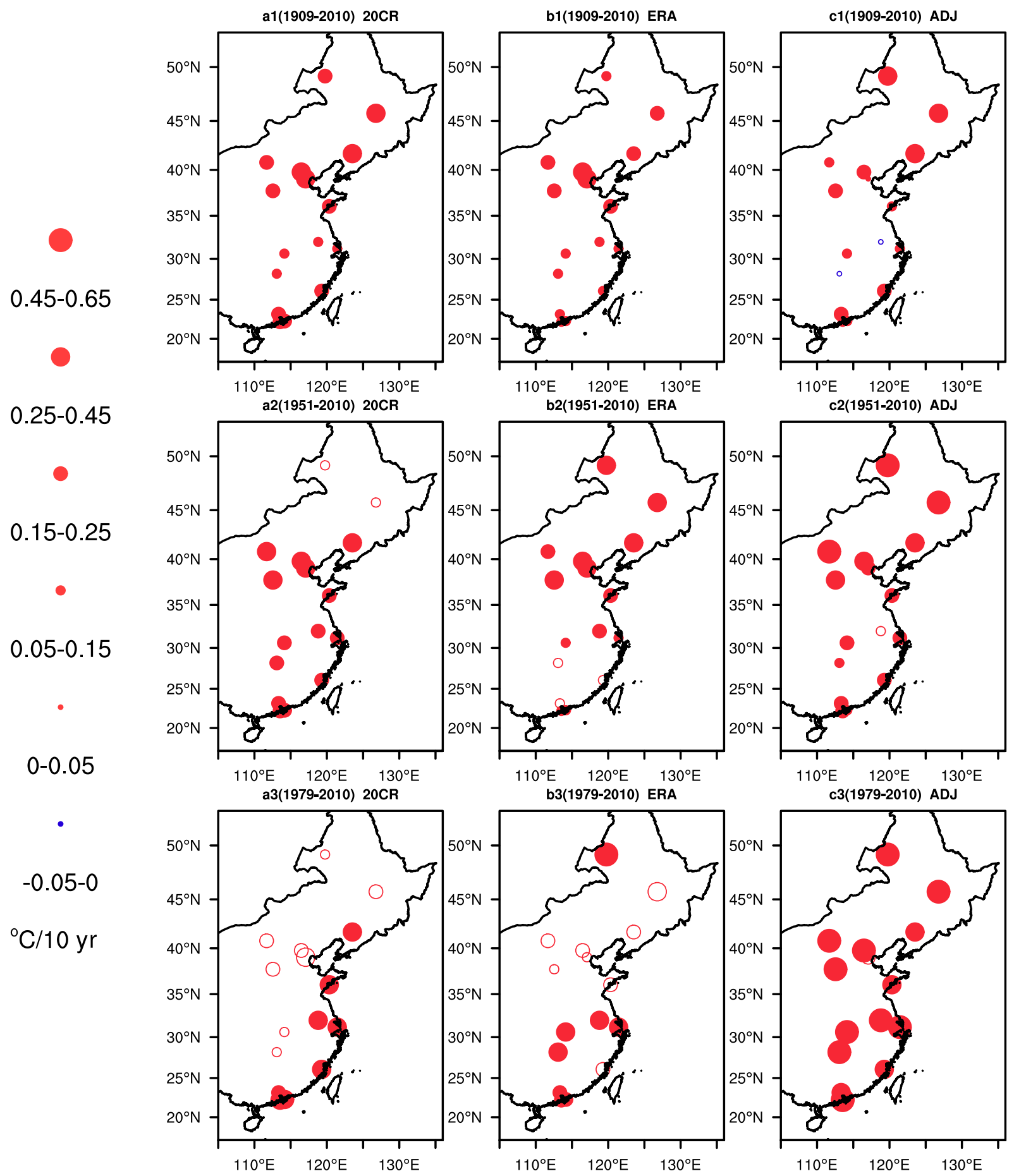

Fig. 8. Spatial distribution of temperature change trends (units: $\left.{ }^{\circ} \mathrm{C}(10 \mathrm{yr})^{-1}\right)$ for the periods $1909-2010$, 19512010, and 1979-2010 over eastern China based on reanalysis datasets (ERA20C and 20CR) and observations (ADJ). Solid and empty circles denote that the change is significant or not significant at the $95 \%$ confidence level, respectively. 
cant increases of 20CR temperature were mainly distributed in coastal areas, and those for ERA20C were mainly distributed south of the Yangtze River. The increasing trend of ADJ during the recent 30 years was higher than that during 1951-2010. It was also obvious that the trend of REA for 1979-2010 appeared to be smaller than that of ADJ even in north and Northeast China. The linear trends of surface air temperature showed clear warming in both reanalysis datasets and the observations from 1979 to 2010 over eastern China (Zhou et al. 2018).

\section{Conclusions and discussion}

Based on homogenized observation data from 16 stations in eastern China and two 20th century monthly mean surface temperature reanalysis datasets $(20 \mathrm{CR}$ and ERA20C), a preliminary comparison of the anomaly difference, correlation, standard deviation, and linear trend of the temperature data was conducted for the periods 1909-2010, 1951-2010, and 1979-2010. The main findings were as follows:

(1) For ERA20C and 20CR, there was a high consistency with ADJ in annual variation characteristics after 1975. There were large fluctuations of REA during 1960-1970. The differences between 20CR and ADJ were large before the 1950s, and ERA20C was generally closer to ADJ. The annual variation characteristics of REA had a higher agreement with those of ADJ in winter and spring than in summer and autumn.

(2) Most of the stations showed high consistency with ADJ in inter-annual variability and dispersion, but the consistency at Nanjing, Changsha, Tianjin, and Hohhot stations was relatively low. The $R$ values of ERA20C and ADJ were higher than those of 20CR and ADJ in different periods, and the standard deviation of ERA20C was lower than that of ADJ. The standard deviation of 20CR was higher than that of ADJ during 1909-2010 and 1951-2010. In general, ERA20C was closer to ADJ than 20CR. The bias between REA and observation was mainly generated in summer and autumn, with minimal deviation in winter.

(3) The annual mean temperature of REA, ADJ, and ADJ-T increased significantly in different time periods. The annual mean temperature trends of REA were higher than those of ADJ and ADJ-T during 1909-2010 and were lower in 1951-2010 and 19792010. The linear trends of ADJ were higher than those of ADJ-T. The temperature trends in most seasons of ADJ and ADJ-T were lower than those of 20CR during 1909-2010. The trend of ERA20C was larger than that of ADJ and ADJ-T for summer and autumn, but smaller for winter and spring. The temperature trends of ADJ and ADJ-T were generally higher than those of REA in 1951-2010 and 1979-2010. In winter and spring, and most periods for autumn and summer, ADJ trends were higher than those of ADJ-T.

The results of the linear trends analysis presented here indicate that annual mean temperature trend of ADJ was higher than previous estimates (Ren et al. 2017). The annual mean temperature change trend in China was generally between 0.08 and $0.12(10 \mathrm{yr})^{-1}$ during 1901-2015 (Wang et al. 1998; Tang et al. 2005, 2009; Li et al. 2010). Ren et al. (2017) suggested that a higher warming rate may be related to urbanization bias in single-station sequences and may also be associated with the use of a low number of stations from cities located in eastern and central China. Since the middle of the 20th century, the temperature observation records of urban stations and national meteorological station networks have obtained a significant urbanization bias, regardless of whether homogenization corrections were applied (Ren et al. 2008, 2015; Zhao et al. 2009; Zhang et al. 2010; Yang et al. 2011; Wang and Ge 2012; He et al. 2013). This clearly indicates that although the linear trends of REA data may have been more correct than those of the observations for the recent decades, they may have been largely overestimated relative to the real trends based on the urban-bias adjusted observations for the period 1909-2010. It is premature at present to use the REA data for estimating the long-term trends of surface air temperature in regions such as eastern China.

Correction of urbanization bias is important for studies of long-term surface air temperature changes at individual stations. This paper represents a preliminary comparison of surface air temperatures between observation and reanalysis data over eastern China for the last 100 years. In future, urban-bias assessment and adjustments must be conducted, and both a larger study area and longer observation period are required to conduct a more detailed comparison and uncertainty study.

\section{Acknowledgments}

This study is financed by the National Key Research and Development Program of China (No.2018 YFA0605603), China Natural Science Foundation (CNSF) (Fund No: 41575003), China Meteorological Administration Special Foundation for Climate Change (grant number CCSF201803) and Special Fund for Meteorological Scientific Research in the Public Interest "The 40-year CMA Global Atmospher- 
ic Reanalysis (CRA-40): Technique Research and Products" (GYHY 201506002). This work and its contributors (SiQi Zhang, GuoYu Ren, YuYu Ren, XiuBao Sun) were also supported by the UK-China Research \& Innovation Partnership Fund through the Met Office Climate Science for Service Partnership (CSSP) China as part of the Newton Fund. We thank LetPub (http://www.letpub.com) for its linguistic assistance during the preparation of this manuscript.

\section{References}

Bengtsson, L., S. Hagemann, and K. I. Hodges, 2004: Can climate trends be calculated from reanalysis data? J. Geophys. Res., 109, D11111, doi:10.1029/2004JD 004536.

Cao, L., P. Zhao, Z. Yan, P. Jones, Y. Zhu, Y. Yu, and G. Tang, 2013: Instrumental temperature series in eastern and central China back to the nineteenth century. $J$. Geophys. Res., 118, 8197-8207.

Compo, G. P., J. S. Whitaker, P. D. Sardeshmukh, N. Matsui, R. J. Allan, X. Yin, B. E. Gleason, R. S. Vose, G. Rutledge, P. Bessemoulin, S. Brönnimann, M. Brunet, R. I. Crouthamel, A. N. Grant, P. Y. Groisman, P. D. Jones, M. C. Kruk, A. C. Kruger, G. J. Marshall, M. Maugeri, H. Y. Mok, Ø. Nordli, T. F. Ross, R. M. Trigo, X. L. Wang, S. D. Woodruff, and S. J. Worley, 2011: The twentieth century reanalysis project. Quart. J. Roy. Meteor. Soc., 137, 1-28.

Dee, D. P., S. M. Uppala, A. J. Simmons, P. Berrisford, P. Poli, S. Kobayashi, U. Andrae, M. A. Balmaseda, G. Balsamo, P. Bauer, P. Bechtold, A. C. M. Beljaars, L. van de Berg, J. Bidlot, N. Bormann, C. Delsol, R. Dragani, M. Fuentes, A. J. Geer, L. Haimberger, S. B. Healy, H. Hersbach, E. V. Hólm, L. Isaksen, P. Kållberg, M. Köhler, M. Matricardi, A. P. McNally, B. M. Monge-Sanz, J.-J. Morcrette, B.-K. Park, C. Peubey, P. de Rosnay, C. Tavolato, J.-N. Thépaut, and F. Vitart, 2011: The ERA-Interim reanalysis: Configuration and performance of the data assimilation system. Quart. J. Roy. Meteor. Soc., 137, 553-597.

Easterling, D. R., and T. C. Peterson, 1995: A new method for detecting undocumented discontinuities in climatological time series. Int. J. Climatol., 15, 369-377.

Fan, K., and H. Liu, 2013: Evaluation of atmospheric circulation in the Southern Hemisphere in 20CRv2. Atmos. Oceanic Sci. Lett., 6, 337-342.

Ferguson, C. R., and G. Villarini, 2012: Detecting inhomogeneities in the Twentieth Century Reanalysis over the central United States. J. Geophys. Res., 117, D05123, doi:10.1029/2011JD016988.

He, Y. T., G. S. Jia, Y. H. Hu, and Z. H. Zhou, 2013: Detecting urban warming signals in climate records. $A d v$. Atmos. Sci., 30, 1143-1153.

Kalnay, E., M. Kanamitsu, R. Kistler, W. Collins, D. Deaven, L. Gandin, M. Iredell, S. Saha, G. White,
J. Woollen, Y. Zhu, M. Chelliah, W. Ebisuzaki, W. Higgin, J. Janowiak, K. C. Mo, C. Ropelewski, J. Wang, A. Leetmaa, R. Reynolds, R. Jenne, and D. Joseph, 1996: The NCEP/NCAR 40-Year Reanalysis Project. Bull. Amer. Meteor. Soc., 77, 437-471.

Kanamitsu, M., W. Ebisuzaki, J. Woollen, S.-K. Yang, J. J. Hnilo, M. Fiorino, and G. L. Potter, 2002: NCEPDOE AMIP-II reanalysis (R-2). Bull. Amer. Meteor. Soc., 83, 1631-1643.

Kistler, R., E. Kalnay, W. Collins, S. Saha, G. White, J. Woollen, M. Chelliah, W. Ebisuzaki, M. Kanamitsu, V. Kousky, H. van den Dool, R. Jenne, and M. Fiorino, 2001: The NCEP-NCAR 50-Year Reanalysis: Monthly means CD-ROM and documentation. Bull. Amer. Meteor. Soc., 82, 247-267.

Kobayashi, S., Y. Ota, Y. Harada, A. Ebita, M. Moriya, H. Onoda, K. Onogi, H. Kamahori, C. Kobayashi, H. Endo, K. Miyaoka, and K. Takahashi, 2015: The JRA55 Reanalysis: General specifications and basic characteristics. J. Meteor. Soc. Japan, 93, 5-48.

Lahoz, W. A., and P. Schneider, 2014: Data assimilation: Making sense of Earth Observation. Front. Environ. Sci., 2, 1-28.

Li, Q. X., W. J. Dong, W. Li, X. R. Gao, P. Jones, J. Kenedy, and D. Parker, 2010: Estimate of uncertainties in temperature change of China over the last 100 years. Chinese Sci. Bull., 2010, 1544-1554 (in Chinese).

Liu, H., and K. Fan, 2014: Eurasia seasonal circulation climatology and variability: Evaluation of $20 \mathrm{CR}$ reanalysis data in Eurasia and East China. Chinese J. Atmos. Sci., 38, 469-483 (in Chinese).

Onogi, K., J. Tsutsui, H. Koide, M. Sakamoto, S. Kobayashi, H. Hatsushika, T. Matsumoto, N. Yamazaki, H. Kamahori, K. Takahashi, S. Kadokura, K. Wada, K. Kato, R. Oyama, T. Ose, N. Mannoji, and R. Taira, 2007: The JRA-25 Reanalysis. J. Meteor. Soc. Japan, 85, 369-432.

Parker, W. S., 2016: Reanalyses and observations: What's the difference? Bull. Amer. Meteor. Soc., 97, 15651572.

Poli, P., H. Hersbach, D. Tan, D. Dee, J.-N. Thépaut, A. Simmons, C. Peubey, P. Laloyaux, T. Komori, P. Berrisford, R. Dragani, Y. Trémolet, E. Hólm, M. Bonavita, L. Isaksen, and M. Fisher, 2013: The data assimilation system and initial performance evaluation of the ECMWF pilot reanalysis of the 20th-century assimilating surface observations only (ERA-20C). ERA Rep. Ser., 14, ECMWF, 59 pp.

Poli, P., H. Hersbach, D. P. Dee, P. Berrisford, A. J. Simmons, F. Vitart, P. Laloyaux, D. G. H. Tan, C. Peubey, J.-N. Thépaut, Y. Thépaut, E.V. Hólm, M. Bonavita, L. Isaksen, and M. Fisher, 2016: ERA-20C: An atmospheric reanalysis of the 20th century. J. Climate, 29, 4083-4097.

Ren, G., Y. Zhou, Z. Chu, J. Zhou, A. Zhang, J. Guo, and X. Liu, 2008: Urbanization effects on observed surface 
air temperature trends in north China. J. Climate, 21, 1333-1348.

Ren, G., J. Li, Y. Ren, Z. Chu, A. Zhang, Y. Zhou, L. Zhang, Y. Zhang, and T. Bian, 2015: An integrated procedure to determine a reference station network for evaluating and adjusting urban bias in surface air temperature data. J. Appl. Meteor. Climatol., 54, 1248-1266.

Ren, G., Y. Ding, and G. Tang, 2017: An overview of mainland China temperature change research. Acta Meteor. Sinica, 31, 3-16.

Rienecker, M. M., M. J. Suarez, R. Gelaro, R. Todling, J. Bacmeister, E. Liu, M. G. Bosilovich, S. D. Schubert, L. Takacs, G.-K. Kim, S. Bloom, J. Chen, D. Collins, A. Conaty, A. da Silva, W. Gu, J. Joiner, R. D. Koster, R. Lucchesi, A. Molod, T. Owens, S. Pawson, P. Pegion, C. R. Redder, R. Reichle, F. R. Robertson, A. G. Ruddick, M. Sienkiewicz, and J. Woollen, 2011: MERRA: NASA's modern-era retrospective analysis for research and applications. J. Climate, 24, 36243648.

Saha, S., S. Moorthi, H.-L. Pan, X. Wu, J. Wang, S. Nadiga, P. Tripp, R. Kistler, J. Woollen, D. Behringer, H. Liu, D. Stokes, R. Grumbine, G. Gayno, J. Wang, Y.-T. Hou, H.-Y. Chuang, H.-M. H. Juang, J. Sela, M. Iredell, R. Treadon, D. Kleist, P. Van Delst, D. Keyser, J. Derber, M. Ek, J. Meng, H. Wei, R. Yang, S. Lord, H. van den Dool, A. Kumar, W. Wang, C. Long, M. Chelliah, Y. Xue, B. Huang, J.-K. Schemm, W. Ebisuzaki, R. Lin, P. Xie, M. Chen, S. Zhou, W. Higgins, C.-Z. Zou, Q. Liu, Y. Chen, Y. Han, L. Cucurull, R. W. Reynolds, G. Rutledge, and M. Goldberg, 2010: The NCEP Climate Forecast System Reanalysis. Bull. Amer. Meteor. Soc., 91, 1015-1057.

Song, F., and T. Zhou, 2012: Reliability of the 20CR reanalysis data in measuring the East Asian summer monsoon variability. Chinese J. Atmos. Sci., 36, 12071222 (in Chinese).

Tang, G. L., and G. Ren, 2005: A reanalysis of surface air temperature change of the last 100 years over China. Climatic Environ. Res., 10, 791-798.

Tang, G. L., Y. H. Ding, S. W. Wang, G. Ren, H. Liu, and L. Zhang, 2009: Comparative analysis of the time series of surface air temperature over China for the last 100 years. Adv. Clim. Change Res., 5, 71-78 (in Chinese).

Thorne, P. W., and R. S. Vose, 2010: Reanalyses suitable for characterizing long-term trends. Are they really achievable? Bull. Amer. Meteor. Soc., 91, 353-361.

Uppala, S. M., P. W. Kållberg, A. J. Simmons, U. Andrae, V. Da Costa Bechtold, M. Fiorino, J. K. Gibson, J. Haseler, A. Hernandez, G. A. Kelly, X. Li, K. Onogi, S. Saarinen, N. Sokka, R. P. Allan, E. Andersson, K. Arpe, M. A. Balmaseda, A. C. M. Beljaars, L. Van De Berg, J. Bidlot, N. Bormann, S. Caires, F. Chevallier, A. Dethof, M. Dragosavac, M. Fisher, M. Fuentes, S. Hagemann, E. Hólm, B. J. Hoskins, L. Isaksen, P. A. E. M. Janssen, R. Jenne, A. P. Mcnally, J.-F. Mahfouf,
J.-J. Morcrette, N. A. Rayner, R. W. Saunders, P. Simon, A. Sterl, K. E. Trenberth, A. Untch, D. Vasiljevic, P. Viterbo, and J. Woollen, 2005: The ERA-40 re-analysis. Quart. J. Roy. Meteor. Soc., 131, 29613012.

Uppala, S. M., D. Dee, S. Kobayashi, P. Berrisford, and A. Simmons, 2008: Towards a climate data assimilation system: Status update of ERA-Interim. ECMWF Newsletter, 115, 12-18.

Wang, F., and Q. S. Ge, 2012: Estimation of urbanization bias in observed surface temperature change in China from 1980 to 2009 using satellite land-use data. Chinese Sci. Bull., 57, 1708-1715.

Wang, J., C. Xu, M. Hu, Q. Li, Z. Yan, P. Zhao, and P. Jones, 2014: A new estimate of the China temperature anomaly series and uncertainty assessment in 1900-2006. J. Geophys. Res., 119, 1-9.

Wang, S., J. Ye, D. Gong, J. Zhu, and T. Yao, 1998: Construction of mean annual temperature series for the last one hundred years in China. J. Appl. Meteor. Sci., 9, 392-401 (in Chinese).

Wang, X. L., 2008: Accounting for autocorrelation in detecting mean shifts in climate data series using the penalized maximal $t$ or $F$ test. J. Appl. Meteor. Climatol., 47, 2423-2444.

Xu, Y., Y. H. Ding, and Z. Zhao, 2001: Confidence analysis of NCEP/NCAR 50-year global reanalyzed data in climate change research in China. J. Appl. Meteor. Sci., 12, 337-347 (in Chinese).

Yang, X., Y. Hou, and B. Chen, 2011: Observed surface warming induced by urbanization in east China. $J$. Geophys. Res., 116, D14113, doi:10.1029/2010JD 015452.

Zhang, A. Y., G. Y. Ren, J. X. Zhou, Z. Y. Chu, Y. Y. Ren, and G. L. Tang, 2010: On the urbanization effect on surface air temperature trends over China. Acta Meteor. Sinica, 68, 957-966 (in Chinese).

Zhao, P., P. Jones, L. J. Cao, Z. W. Yan, S. Zha, Y. Zhu, Y. $\mathrm{Yu}$, and G. L. Tang, 2014: Trend of surface air temperature in eastern China and associated large-scale climate variability over the last 100 years. J. Climate, 27, 4693-4703.

Zhao, T., C. Fu, Z. Ke, and W. Guo, 2010: Global atmosphere reanalysis datasets: Current status and recent advances. Adv. Earth Sci., 25, 242-254 (in Chinese).

Zhao, T., J. Wang, and A. Dai, 2015: Evaluation of atmospheric precipitable water from reanalysis products using homogenized radiosonde observations over China. J. Geophys. Res., 120, 10703-10727.

Zhao, Z., S. Wang, Y. Luo, and Y. Jiang, 2009: Uncertainty analysis of climate warming during the last 100 years. Sci. Technol. Rev., 27, 41-48 (in Chinese).

Zhou, C., Y. He, and K. Wang, 2018: On the suitability of current atmospheric reanalysis for regional warming studies over China. Atmos. Chem. Phys., 18, 81138136. 